\title{
A novel inborn error of the Coenzyme Q10 biosynthesis pathway: Cerebellar ataxia and static encephalomyopathy due to COQ5 C-Methyltransferase deficiency
}

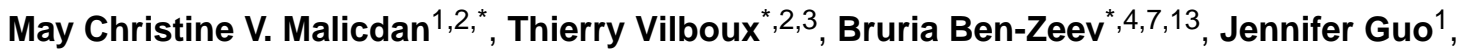 \\ Aviva Eliyahu $^{5,7}$, Ben Pode-Shakked ${ }^{5,6,7}$, Amir Dori ${ }^{6,7,8}$, Sravan Kakani ${ }^{2}$, Settara C. \\ Chandrasekharappa $^{9}$, Carlos Ferreira ${ }^{2}$, Natalia Shelestovich ${ }^{7,12}$, Dina Marek-Yage $\mathrm{I}^{5,7,13}$, \\ Hadass Pri-Chen ${ }^{2,14}$, Ilan Blatt ${ }^{10}$, John E. Niederhuber ${ }^{3,16}$, Langping He ${ }^{11}$, Camilo Toro ${ }^{1}$, \\ Robert W. Taylor ${ }^{11}$, John Deeken ${ }^{3}$, Tal Yardeni ${ }^{12}$, Douglas C. Wallace ${ }^{12}$, William A. \\ Gahl $^{1,2,{ }^{* *} \text {, and Yair Anikster }}{ }^{5,7,14,{ }^{* *}}$ \\ ${ }^{1} \mathrm{NIH}$ Undiagnosed Diseases Program, Common Fund, Office of the Director, NIH and National \\ Human Genome Research Institute, NIH, Bethesda, 20892 Maryland, USA \\ ${ }^{2}$ Medical Genetics Branch, National Human Genome Research Institute, National Institutes of \\ Health, Bethesda, 20892 Maryland, USA \\ ${ }^{3}$ Inova Translational Medicine Institute, Falls Church, 22042 Virginia, USA \\ ${ }^{4}$ Pediatric Neurology Unit, Edmond and Lily Safra Children's Hospital, Sheba Medical Center, Tel- \\ Hashomer, 5621 Israel \\ ${ }^{5}$ Metabolic Disease Unit, Edmond and Lily Safra Children's Hospital, Sheba Medical Center, Tel- \\ Hashomer, 5621 Israel \\ ${ }^{6}$ The Dr. Pinchas Borenstein Talpiot Medical Leadership Program, Sheba Medical Center, Tel- \\ Hashomer, 5621 Israel \\ ${ }^{7}$ Sackler Faculty of Medicine, Tel-Aviv University, Tel-Aviv, 69978 Israel \\ 8Joseph Sagol Neuroscience Center, Sackler Faculty of Medicine, Tel Aviv University, Tel Aviv, \\ 69978 Israel \\ ${ }^{9}$ Cancer Genetics and Comparative Genomics Branch, National Human Genome Research \\ Institute, National Institutes of Health, Bethesda, 20892 Maryland, USA \\ 10Department of Neurology, Sheba Medical Center, Tel-Hashomer, 5621 Israel
}

Corresponding Authors: Yair Anikster, M.D., Ph.D., Metabolic Disease Unit, Edmond and Lily Safra Children's Hospital, Sheba Medical Center, Tel-Hashomer, 52621, Israel. yair.anikster@sheba.health.gov.il. Bruria Ben-Zeev, M.D., Pediatric Neurology Unit, Edmond and Lily Safra Children's Hospital, Sheba Medical Center, Tel-Hashomer, 52621, Israel.

Bruria.BenZeev@ sheba.health.gov.il. May Christine V. Malicdan, M.D., PhD., NIH Undiagnosed Diseases Program, Common Fund,

Office of the Director, NIH and National Human Genome Research Institute, NIH, Bethesda, 20892 Maryland, USA.

malicdanm@mail.nih.gov.

** These authors contributed equally to the manuscript

** These authors contributed to the manuscript and are senior authors

Competing Interests Statement

The authors declare that they have no competing financial interests. 
${ }^{11}$ Wellcome Centre for Mitochondrial Research, Institute of Neuroscience, The Medical School, Newcastle University, Newcastle upon Tyne, UK

${ }^{12}$ Center for Mitochondrial and Epigenomic Medicine, Children's Hospital of Philadelphia Research Institute, Philadelphia, USA

${ }^{13}$ Department of Pathology, Sheba Medical Center, Tel-Hashomer, 52621, Israel

${ }^{14}$ The Wohl Institute for Translational Medicine, Sheba Medical Center, Tel-Hashomer, 52621, Israel

${ }^{15}$ Graduate Partnership Program (GPP), National Institute of Health (NIH) Bethesda, 20892

Maryland, USA and Sackler Faculty of Medicine, Tel-Aviv University, Tel-Aviv, 69978 Israel

${ }^{16}$ Johns Hopkins University School of Medicine, 733 North Broadway Street, Baltimore, MD, USA

\section{Abstract}

Primary coenzyme Q10 ( $\mathrm{CoQ}_{10}$; MIM\# 607426) deficiencies are an emerging group of inherited mitochondrial disorders with heterogonous clinical phenotypes. Over a dozen genes are involved in the biosynthesis of $\mathrm{CoQ}_{10}$, and mutations in several of these are associated with human disease. However, mutations in COQ5 (MIM\# 616359), catalyzing the only C-methylation in the $\mathrm{CoQ}_{10}$ synthetic pathway, have not been implicated in human disease.

Here, we report three female siblings of Iraqi-Jewish descent, who had varying degrees of cerebellar ataxia, encephalopathy, generalized tonic-clonic seizures and cognitive disability. Whole exome and subsequent whole genome sequencing identified biallelic duplications in the COQ5 gene, leading to reduced levels of $\mathrm{CoQ}_{10}$ in peripheral white blood cells of all affected individuals and reduced $\mathrm{CoQ}_{10}$ levels in the only muscle tissue available from one affected proband. $\mathrm{CoQ}_{10}$ supplementation led to clinical improvement and increased the concentrations of $\mathrm{CoQ}_{10}$ in blood.

This is the first report of primary $\mathrm{CoQ}_{10}$ deficiency caused by loss of function of $C O Q 5$, with delineation of the clinical, laboratory, histological and molecular features, and insights regarding targeted treatment with $\mathrm{CoQ}_{10}$ supplementation.

\section{Keywords}

COQ5; $\mathrm{CoQ}_{10}$; Cerebellar ataxia; encephalopathy; personalized medicine; next generation sequencing

\section{Introduction}

Coenzyme Q (ubiquinone) is a lipophilic redox molecule, essential for diverse cellular roles, including as an electron carrier, regulator of transition pores, and a substrate for pyrimidine nucleotide synthesis. It also acts as an antioxidant and a modulator of fatty acid $\beta$-oxidation. Indeed, it links FAO to mitochondrial respiratory chain through electron transfer flavoprotein (ETF) and ETF:ubiquinone oxidoreductase (ETFQO). Following the characterization of their yeast counterparts, the human Coenzyme Q gene family was shown to include over 13 genes involved in the biosynthesis of $\mathrm{CoQ}_{10}$; at least eight of these are associated with human disorders (Doimo, et al., 2014).

Hum Mutat. Author manuscript; available in PMC 2019 January 01. 
Diseases of $\mathrm{CoQ}_{10}$ deficiency have been reported in over 100 individuals worldwide. Their heterogeneous clinical features are consistent with one of five major phenotypes (Quinzii, et al., 2014): 1) Encephalopathy, associated with mitochondrial myopathy and myoglobinuria (Boitier, et al., 1998; Ogasahara, et al., 1989; Salviati, et al., 2012; Sobreira, et al., 1997); 2) Severe infantile disease with multi-systemic involvement (Desbats, et al., 2015; Dinwiddie, et al., 2013; Quinzii, et al., 2006; Rotig, et al., 2000); 3) Ataxia with cerebellar atrophy, the most common form, variably associated with seizures, cognitive impairment, muscle weakness, neuropathy and hypogonadism (Gironi, et al., 2004; Lagier-Tourenne, et al., 2008; Musumeci, et al., 2001); 4) Nephropathy, with or without sensory hearing loss (Ashraf, et al., 2013; Diomedi-Camassei, et al., 2007; Heeringa, et al., 2011; McCarthy, et al., 2013); and 5) Isolated myopathy (Gempel, et al., 2007; Horvath, et al., 2006; Lalani, et al., 2005). In the past decade, next-generation sequencing techniques have facilitated molecular diagnosis of these patients, enabling further elucidation of genotype-phenotype correlations (Yubero, et al., 2014). Of the numerous human mitochondrial disorders, $\mathrm{CoQ}_{10}$ deficiency is considered the only currently treatable disorder, since patients often respond to oral $\mathrm{CoQ}_{10}$ supplementation (DiMauro, et al., 2007; Garrido-Maraver, et al., 2014).

While several genes in the $\mathrm{CoQ}_{10}$ biosynthesis pathway have been implicated in primary $\mathrm{CoQ}_{10}$ deficiency (MIM 607426), no human phenotype attributable to COQ5 mutations has been described. Coq5 is an important enzyme that catalyzes the only C-methylation step involved in the synthesis of $\mathrm{Coq}_{10}$ in yeast and mammalian cells (Baba, et al., 2004;

Barkovich, et al., 1997; Nguyen, et al., 2014), and has been shown to assemble with a multisubunit Coq polypeptide complex (He, et al., 2014). It is expressed in multiple tissues but highest in liver, lung, placenta, and skeletal muscle.

We report for the first time patients with encephalomyopathy, cerebellar ataxia and additional findings in a multiplex non-consanguineous family with CoQ10 deficiency due to a biallelic duplication in COQ5.

\section{Methods}

Patients

Patients and family members were enrolled in NIH protocol 76-HG-0238, "Diagnosis and Treatment of Patients with Inborn Errors of Metabolism or Other Genetic Disorders", approved by the Institutional Review Board of the National Human Genome Research Institute (NHGRI). The patients gave written, informed consent. Clinical evaluations were performed at the Pediatric Neurology Unit at the Edmond and Lily Safra Children's Hospital, Sheba Medical Center, Tel-Hashomer, Israel.

\section{Single-Nucleotide Polymorphism Arrays}

Single-nucleotide polymorphism (SNP) genotyping was performed on genomic DNA with the use of the HumanOmniExpress DNA Analysis BeadChip (Illumina). SNPs were analyzed using GenomeStudio software (Illumina) (Peiffer, et al., 2006; Steemers and Gunderson, 2007). 


\section{Next Generation Sequencing}

For whole exome sequencing, the library preparation method was performed using the SureSelect Human All-Exon System version 1.0 (Agilent Technologies). Sequencing was performed with the use of the Genome Analyzer IIx sequencer (Illumina). For whole genome sequencing, the library preparation method was performed using the Illumina TruSeq Nano. Sequencing was performed with the Illumina HiSeq X Ten sequencer (Illumina). Variants were filtered and visualized using the graphical software tool VarSifter v1.5 (Teer, et al., 2012).

\section{Biochemistry}

Blood samples were drawn at baseline and at different time points during CoQ supplementation into acid citrate dextrose tubes and were submitted for $\mathrm{CoQ}_{10}$ analyte measurement in leukocytes by a clinical laboratory (https://mnglabs.com). A piece of a muscle biopsy from one of the affected patients was flash-frozen and subjected to $\mathrm{CoQ}_{10}$ measurement by a clinical laboratory using high performance liquid chromatography (http:// www.rgbmgl.org). Other pieces were fixed in formalin and embedded in paraffin for cytochrome c oxidase staining.

\section{PCR and Sanger sequencing}

For PCR and dideoxy sequencing, specific primers were designed (sequences available upon request) to amplify the regions of interest. Direct sequencing of the PCR products was performed using BigDye 3.1 Terminator chemistry (Applied Biosystems) and analyzed on an ABI3130xl genetic analyzer (Applied Biosystems). Data were evaluated using Sequencher v5.0 software (Gene Codes Corporation, Ann Arbor, MI). Variants identified were submitted to ClinVar (https://www.ncbi.nlm.nih.gov/clinvar/).

\section{Copy Number Analysis}

Copy number analysis by quantitative PCR (qPCR) was performed using 3 TaqMan probes in the duplicating area (Hs00355860_cn, Hs06353017_cn and Hs00837086_cn), 2 flanking the duplicated area (Hs01474184_cn and Hs07018271_cn) and an endogenous control probe in the GAPDH gene (Hs00894322_cn). All the probes were purchased from Applied Biosystems (Foster City, CA). All the qPCR experiments were performed in triplicate as described (Vilboux, et al., 2011) on an ABI PRISM 7900 HT Sequence Detection System (Applied Biosystems). The comparative $\mathrm{Ct}$ method was used to determine the copy number (Livak and Schmittgen, 2001).

\section{Analysis of COQ5 expression in fibroblasts}

Fibroblasts from III.6 were grown as explants from skin biopsies in 10\% FBS in DMEM (Malicdan, et al., 2015). Control fibroblasts were purchased from ATCC. Total RNA was isolated from fibroblasts with the RNeasy Mini Kit (Qiagen, Valencia, CA, USA) and treated with a DNase kit (DNA-free) according to the manufacturer's protocol (Life Technologies, Carlsbad, CA, USA). RNA concentration and purity were assessed and first strand cDNA was synthesized using a high capacity RNA-to-cDNA kit (Applied Biosystems). Reverse Transcriptase reaction products were amplified using specific primers (sequences available 
upon request) and loaded into $2 \%$ agarose gel. Sanger sequencing of the excised bands was performed as mentioned above. Quantitative real-time PCR (qRTPCR) was performed using TaqMan Gene Expression Master Mix reagent (Applied Biosystems) and carried out on an ABI PRISM 7900 HT Sequence Detection System (Applied Biosystems) for total COQ5 mRNA expression (Taqman probes ID). Power SYBR Green PCR master mix (Applied Biosystems, Woolston, Warrington, UK) and qPCR machine with standard qPCR parameters were used to analyze the expression of the different COQ5 isoforms. Results were analyzed with the comparative CT method as described (Livak and Schmittgen, 2001).

For western blots, cell lysates were prepared using RIPA buffer supplemented with protease inhibitors, and lysed using 30 strokes with a Dounce homogenizer. Mitochondrial fractions were prepared using the Mitochondria Isolation Kit for Culture Cells (Abcam) per the manufacturer's instructions. Samples were electrophoresed on a 4\%-12\% Bis-Tris gel and blotted onto a $0.2 \mu \mathrm{m}$ nitrocellulose membrane. Membranes were blocked with Odyssey ${ }^{\circledR}$ Blocking Buffer (PBS), washed and incubated with primary goat anti-human COQ5 antibody (Santa Cruz Biotechnology), mouse anti-beta actin antibody (Abcam), followed by appropriate IRDye 680RD or IRDye 800CW-conjugated secondary antibodies (Li-Cor Biosciences). Antibodies were diluted in Odyssey® Blocking Buffer (PBS).

Nuclear and cytosolic fractions were prepared using the rapid, efficient, and practical (REAP) method (Suzuki, et al., 2010). Cells were scraped into 1x PBS, pelleted, and lysed in $0.1 \%$ NP40-PBS buffer. Samples were then pelleted briefly and the supernatant was taken as the cytosolic fraction. The pellet was resuspended in 0.1\% NP40-PBS buffer, spun down once more, and the resulting nuclear pellet was dissolved in 1x Laemmli Sample Buffer (Bio-Rad) and used as the nuclear fraction. Samples were electrophoresed as above.

\section{Oxygen consumption measurement in human fibroblasts}

Human fibroblasts were measured for the mitochondrial oxygen consumption rate (OCR) by using the Seahorse XF24 Instrument (Seahorse Bioscience, Billerica, MD). Wild-type control and patient fibroblast cells were plated on XF-24 plates 48 hours before the analysis at 20,000 cells per well and grown in DMEM which contained $25 \mathrm{mM}$ glucose, $10 \%$ FBS and $1 \%$ MEM Non-Essential amino acid at $37^{\circ} \mathrm{C}$ with $5 \% \mathrm{CO}$. Twenty minutes prior to the analysis, the culture medium was replaced by unbuffered DMEM XF Base medium (Seahorse Bioscience) at pH 7.4 contained with $5 \mathrm{mM}$ glucose, $2 \mathrm{mM}$ GlutaMAX and $1 \mathrm{mM}$ sodium pyruvate, and the plates were incubated at $37^{\circ} \mathrm{C}$ in a $\mathrm{CO} 2$-free incubator. The mitochondrial OCR was measured under the following conditions: (1) basal, and after the addition of (2) $1.25 \mu \mathrm{M}$ oligomycin, (3) $0.2 \mu \mathrm{M}$ of the uncoupler, carbonyl cyanide 4(trifluoromethoxy) phenylhydrazone (FCCP) and (4) $1 \mu \mathrm{M}$ of rotenone together with $1.8 \mu \mathrm{M}$ antimycin A. For each condition three cycles of mixing (150 s), waiting (120 s), and measuring $(210 \mathrm{~s})$ were performed. This series was repeated following each injection. Mitochondrial high resolution respirometry in fibroblasts, reflecting the in vivo state of the respiratory chain and oxidative phosphorlyation function, was performed by a clinical laboratory (https://mnglabs.com) (Kenyon and Moraes, 1997; Rossignol, et al., 1999). 


\section{Muscle biopsy and biochemical measurements}

Needle muscle biopsy was processed for muscle histochemistry as previously described (Mozaffar and Pestronk, 2000; Pestronk, et al., 1992). Cryostat sections histochemical stains of rapidly frozen muscle included hematoxylin and eosin, Gomori trichrome, nicotinamide adenine dinucleotide (NADH), cytochrome oxidase (COX), succinate dehydrogenase (SDH), Sudan black (lipid) and adenosine tri-phosphatase (ATPase, pH 9.4, 4.6, and 4.3). Type 2C muscle fiber staining for myosin ATPase activity at $\mathrm{pH} 4.3$ was intermediate between types 1 (dark) and 2 (light) (Brooke and Kaiser, 1970). A total of 197 fibers were counted and the type $2 \mathrm{C}$ fiber frequency was defined as the percentage of $2 \mathrm{C}$ fibers in a random cross-section photomicrograph field. Analysis of $\mathrm{CoQ}_{10}$ levels in the muscle was performed by a clinical diagnostic laboratory. For measuring the activity of individual mitochondrial complexes, we followed our published methods (Kirby, et al., 2007; Taylor, et al., 1993).

\section{Clinical scoring}

Treatment with CoQ supplementation (Ubiquinol; $15 \mathrm{mg} / \mathrm{kg} / \mathrm{d}$ divided into 3 dosages) was given to the 3 affected patients for a period of six months. We used the ICARS (The International Cooperative Ataxia Rating Scale) (Trouillas, et al., 1997) to assess the effect of CoQ supplementation on the various aspects of their cerebellar dysfunction by performing the test at baseline, and 3 and 6 months after initiation of treatment. Due to technical issues, the treatment was stopped by the parents two weeks before the assessment at 6 months.

The ICARS is an outcome measure that was created in 1997 by the Committee of the World Federation of Neurology with the goal of standardizing the quantification of impairment due to cerebellar ataxia. The scale is scored out of 100 with 19 items and 4 subscales of postural and gait disturbances, limb ataxia, dysarthria, and oculomotor disorders. Higher scores indicate higher levels of impairment.

\section{Results}

\section{Patients}

Three female siblings (Fig. 1A), born to non-consanguineous parents of Iraqi-Jewish descent, presented to our center with varying degrees of cerebellar ataxia, encephalopathy, generalized tonic clonic seizures and developmental delay. The proband (III.4), the fourth of seven children, presented in early childhood with short stature and moderate delay in motor and cognitive milestones, followed by non-progressive cerebellar ataxia, dysarthria, mildmoderate cognitive disability, and behavioral problems including impulsivity, short attention span and oppositional characteristics. At approximately 12 years of age, she had myoclonic jerks which were more noticeable during voluntary motor movements. At age 17, she experienced several generalized tonic-clonic seizures. Epilepsy and myoclonus were well controlled by valproic acid combined with low dose clonazepam. On physical examination, the patient showed no dysmorphic features. Her head circumference was $54.5 \mathrm{~cm}\left(35^{\text {th }}\right.$ percentile), and her height was $150 \mathrm{~cm}$ ( -2 Standard Deviations). She had mild horizontal nystagmus, slow saccades with saccadic pursuit and apraxic gaze, normal fundoscopy, dysarthric cerebellar speech, dysmetria in finger-to-nose test, a mild postural and intention 
tremor, ataxic gait and inability to perform tandem walking. She also showed mild lower limb spasticity with brisk tendon joint reflexes and negative Babinski sign.

Brain MRI at 8 and 16 years of age showed mild non-progressive cerebellar atrophy; EEG revealed normal background activity and infrequent generalized polyspike-wave (PSW) discharges; nerve conduction study and cardiac echocardiogram were both normal. Complete blood count, electrolyte levels, CPK, liver and renal function tests, carnitine and acyl-carnitine, copper, ceruloplasmin, thyroid function tests, lactate, pyruvate, ammonia, blood amino acid profile, VLCFA, phytanic acid, homocysteine, isoelectric focusing of transferrin, alpha-FP, quantitative immunoglobulin levels, vitamin E levels, as well as urine for protein and organic acids, were within normal limits.

The proband's older sister (III.3) presented in early childhood (following identification of cerebellar ataxia in her younger sister) with mild static gait ataxia, mild dysarthria, and borderline intelligence (requiring special school only at high school). In her 20's, the patient had myoclonic jerks followed by a single generalized tonic-clonic seizure at the age 22; there was no seizure recurrence on low dose valproic acid, which was later replaced by lamotrigine. The patient gave birth to a healthy baby with no signs of deterioration during her pregnancy. Upon physical examination, she showed mild gait ataxia with inability to perform tandem walking, mild dysmetria and oculomotor apraxia and horizontal nystagmus. A brain MRI showed mild cerebellar atrophy and EEG showed infrequent generalized PSW discharges.

The youngest of the affected siblings, III.6, exhibited mild motor delay followed by mild learning difficulties in school, characterized by slow response rate, relatively poor verbal skills and poor writing. She was first examined at the age of 14 years, when mild cerebellar ataxia with abnormal tandem walking were identified, as well as brisk deep tendon reflexes, negative Babinski, no tremor or dysmetria but mild cerebellar dysarthria and horizontal nystagmus with hypometric saccades.

\section{Next generation sequencing identifies duplication in COQ5}

Because of the Iraqi-Jewish origin of both parents, a homozygote recessive mode of inheritance was suspected. A SNP array study, performed on the parents and all the siblings revealed several areas of homozygous regions (Supp. Table S1), conforming consanguinity in the family; however, there was one homozygous region, from $118.5 \mathrm{Mb}-121 \mathrm{Mb}$ on chromosome 12 (Chr37) (Fig. 1B), which was observed only in the affected children. Whole exome sequencing (WES), performed on patient III.4, did not identify a potential pathogenic variant (data not shown). Whole genome sequencing (WGS) was then pursued on the same individual, but variant analysis again failed to reveal potential pathogenic variant. Analysis of the Bam files showed a significant increase in the number of reads in the candidate locus on chromosome 12 between positions $\sim 120,940,150$ and $\sim 120,949,950$. The average number of reads in this region $(\sim 60 \mathrm{X})$ compared to the rest of the region $(\sim 30 \mathrm{X})$ suggested the presence of 4 copies, i.e., a homozygote duplication) (Fig. 1C).

Sanger sequencing confirmed the breakpoints of this duplication and showed that it was in tandem (Fig. 1C). This duplication, exactly 9,590bp [Chr12(GRCh37):120940098- 
120949687], is between an AluYc (chr12:120939934-120940228) and an AluY (chr12:120949733-120950042); these two Alus have 84\% identity, potentially making this duplication the result of an unbalanced crossing-over between these two Alus. The duplication spanned the last 4 exons of the COQ5 gene. COQ5 encodes for 2-hexaprenyl-6methoxy-1,4-benzoquinone methyltransferase, a C-methyltransferase required in the biosynthesis of $\mathrm{CoQ}_{10}$. This duplication does not alter the original COQ5ORF and is located about $1 \mathrm{~kb}$ after the DNA sequence that encodes the COQ53'UTR (Fig. 1C).

Copy number (CN) analysis, performed on all the family members for whom DNA was available, revealed that the duplication segregated with the disease based on a homozygote recessive model. Indeed, all the affected individuals were homozygous for the duplication $(\mathrm{CN}=4)$, the parents were both carriers $(\mathrm{CN}=3)$, and all the unaffected members were either carriers or homozygous not duplicated $(\mathrm{CN}=2)$ (Fig. 1A). The duplication was analyzed in a cohort of 92 healthy individual from the same ethnic background, and 3 carriers were identified. These results reveal that, in this population, the duplication has a minor allele frequency of approximately $1.5 \%$.

To investigate the potential effect of this duplication on COQ5, we first measured the mRNA expression level. In patient fibroblasts, qRT-PCR using two different probe sets revealed COQ5 mRNA at a level of only $2-4 \%$ of that in control fibroblasts (Fig. 2A). We then demonstrated reduced COQ5 protein expression in patient fibroblasts by western blotting (Fig. 2B). Sequencing of the cDNA demonstrated that part of the $3^{\prime}$ UTR has been spliced off and replaced by the duplicated part of the gene (exon 4 to 7), generating a longer alternative 3'UTR (Fig. 2C).

\section{$C O Q_{10}$ levels are reduced in patient's leukocytes and muscle tissue}

To determine whether the COQ5 deficiency could affect $\mathrm{CoQ}_{10}$ synthesis, we examined $\mathrm{CoQ}_{10}$ levels of affected and unaffected family members. $\mathrm{CoQ}_{10}$ levels were mildly reduced in all three affected patients (III.3, III.4, and III.6), as compared to their unaffected mother (II.2) (Fig. 3A). We then collected a muscle specimen from III.4, that showed increased type $2 \mathrm{C}$ muscle fibers (Fig. 3B), which comprised $\sim 34 \%$ of all the myofibers; in comparison, type $2 \mathrm{C}$ fibers usually comprise $0-6.5 \%$ of the total number of fibers in unaffected young women (Staron, et al., 2000). There were no signs of myopathy, ragged red fibers, mitochondrial dysfunction or structural abnormalities on histochemical analysis (Fig. 3B), but Type 2C muscle fibers were $34 \%$ the total (normal in young women is $0-6.5 \%$ [4]). $\mathrm{CoQ}_{10}$ levels obtained from the skeletal muscle biopsy was reduced, confirming primary $\mathrm{CoQ}_{10}$ deficiency (Fig. 3A; full blot shown as Supp. Figure S1).

\section{Measurement of oxygen consumption and activity of the respiratory complex chain in human fibroblasts}

To understand the metabolic effects in the mitochondria due to the COQ5 mutation, we used the Seahorse analyzer to measure the cellular oxygen consumption rate (OCR) in cultured fibroblasts. The mutation in $C O Q 5$ significantly reduced uncoupled respiration compared to normal (Fig. 3C). Similarly, high resolution respirometry in fibroblasts showed a reduced uncoupling ratio and increased net routine flux control ratio, consistent with decreased 
reserve capacity (Supp. Table S2). In addition, the phosphorylation respiratory control ratio was increased, indicating that a higher proportion of oxidative phosphorylation is activated to drive ATP synthesis. We also measured the activity of the individual complexes of the respiratory complex chain including the combined activity of II and III, on mitochondrial fractions isolated from dermal fibroblasts, following our published methods (Kirby, et al., 2007; Taylor, et al., 1993). Our analysis showed that there is a measurable defect in Complex II+III activity in the cells, using an assay that relies on endogenous CoQ10 to shuttle electrons from succinate to cytochrome $c$ (Supp. Table S3).

\section{Clinical outcome of $\mathrm{CoQ}_{10}$ supplementation in patients with defects in COQ5}

The pre-treatment ICARS scoring was consistent with the relative clinical severity of the disorder for each patient; the more affected patient (III.4) scored 27/100 and the least affected patient (III.6) scored 13/100. After 3 months of $\mathrm{CoQ}_{10}$ treatment, the scores of all three patients decreased significantly (patient $1: 27$ to 14.5 , patient $2: 13$ to 7.5 , and patient 3: 23 to 8.5). In addition, the patients appeared to have a quicker response rate during conversation and better alertness under the $\mathrm{CoQ}_{10}$ supplementation. A follow-up visit was obtained six months after initiation of treatment, and two weeks after halting $\mathrm{CoQ}_{10}$ treatment. Clinical assessment showed slight deterioration in the scoring results compared to the 3-months' assessment rates (patient 1: -22 , patient 2: -8 , patient 3: -11) (Fig. 3D).

\section{Discussion}

We describe for the first time primary $\mathrm{CoQ}_{10}$ deficiency caused by loss of function of COQ5, manifesting with varying degrees of cerebellar ataxia, myoclonic generalized tonic clonic seizures and cognitive disability in three female siblings.

Through careful manual analysis of next generation sequencing results, we identified a tandem duplication affecting the last four exons of $C O Q 5$, possibly the result of homologous recombination between two Alus (AluY and AluYc). Although the duplication is located about $1 \mathrm{~kb}$ after the gene and affects neither the coding sequence nor the $3^{\prime} \mathrm{UTR}$ of the gene, qPCR showed a nearly total absence of expression of COQ5. Sequencing of the residual COQ5 mRNA revealed that the duplication creates an abnormal isoform due to an abnormal splicing event, where the original $3^{\prime}$ UTR is partially deleted and fused with duplicated exons (exons 4 to 7 ), thus creating a new $3^{\prime}$ UTR that appears abnormally long.

Our CNV analysis on 92 unaffected Iraqi-Jewish controls may be much higher than anticipated; this could be due to the fact that the samples came from a single area. We approximate the MAF to be $1.5 \%$, indicating that CoQ5 deficiency remain underdiagnosed. The combination of manual or automated $\mathrm{CNV}$ analysis and next generation sequencing can help detecting this new variant and therefore can potentially provide diagnosis to some patients with idiopathic cerebellar ataxia.

Our study defines a new subtype of primary $\mathrm{CoQ}_{10}$ deficiency due to a loss-of-function mutation in COQ5. We have demonstrated that modest reduction in $\mathrm{CoQ}_{10}$ levels were present in peripheral blood leukocytes of affected patients while in skeletal muscles $\operatorname{CoQ}_{10}$ levels were much more reduced. The overall effect on $\mathrm{CoQ}_{10}$ levels, especially in skeletal 
muscle tissue, are consistent with the importance of COQ5 in ubiquinone synthesis (Chen, et al., 2013; Yen, et al., 2016), and confirm the finding that destabilization of the COQ5containing protein complex in human cells reduces $\mathrm{CoQ}_{10}$ levels (Yen, et al., 2016). It is important to note, however, that although the $\mathrm{CoQ}_{10}$ levels low, there is still some amount of $\mathrm{CoQ}_{10}$ produced in leukocytes and muscle. We hypothesize that in the affected individuals in this study, the respiration rate is limited by the number of $\mathrm{CoQ}_{10}$ molecules within the mitochondrial inner membrane. However, because the defect in the synthesis of $\mathrm{CoQ}_{10}$ is partial, there is only a $33 \%$ reduction the number of $\mathrm{CoQ}_{10}$ molecules, which can be sufficient to sustain the basal respiration rate in fibroblasts but not the maximum respiration rate.

In addition to the biochemical abnormality of $\mathrm{CoQ}_{10}$ deficiency, the finding of increased frequency of type $2 \mathrm{C}$ fibers in morphologically normal muscle in our proband is also consistent with $\mathrm{CoQ}_{10}$ deficiency as previously reported (Sommerville, et al., 2013), where the increase in the number of type $2 \mathrm{C}$ fibers was thought to be due to inhibition of fiber maturation. Type $2 \mathrm{C}$ muscle fibers represent immature fibers, as they are abundant in fetal muscle and normally decline to less than $5 \%$ of fibers by age 1 year (Brooke and Kaiser, 1970). Increased type $2 \mathrm{C}$ fiber frequency after the age of 1 year occurs in active myopathic disorders with prominent muscle fiber regeneration.

In terms of clinical features, our patients had variable degrees of cerebellar ataxia as their main neurological feature; other neurological symptoms were more variable. The most affected patient had mild to moderate cognitive impairment and a seizure disorder, while the least affected sib functioned in the low-to-normal intelligence range and never had seizures or an abnormal EEG. Cerebellar ataxia with cerebellar atrophy is the most common of the five phenotypes described with primary $\mathrm{CoQ}_{10}$ deficiency and is found mainly in COQ8 (ADCK3) deficiency, defined also as autosomal recessive cerebellar ataxia 2 (ARCA2), but can also be seen in several secondary CoQ deficiency syndromes (Balreira, et al., 2014; Chamova, et al., 2012; Maruyama, et al., 2014; Quinzii, et al., 2005). The significant cerebellar involvement in both primary and secondary $\mathrm{CoQ}_{10}$ deficiency conditions may be related to lower content of endogenous $\mathrm{CoQ}_{10}$ in the cerebellum compared to other brain regions, as demonstrated in the rat (Naini, et al., 2003).

In addition to cerebellar ataxia and atrophy, other features described in $\mathrm{CoQ}_{10}$ deficiency syndromes include seizure disorder, dystonia, migraines, cognitive disability and exercise intolerance. Patients in previous reports and in the current study have not shown extra CNS symptoms or signs, except for occasional exercise intolerance, despite reduced levels of $\mathrm{CoQ}_{10}$ in other tissues (Lagier-Tourenne, et al., 2008; Mignot, et al., 2013; Mollet, et al., 2008).

High dose oral supplementation of $\mathrm{CoQ}_{10}$ has been effective in primary (Ashraf, et al., 2013; Doimo, et al., 2014; Heeringa, et al., 2011; Montini, et al., 2008; Salviati, et al., 2005) and secondary $\mathrm{CoQ}_{10}$ deficiency syndromes (Musumeci, et al., 2001; Quinzii, et al., 2005), and in cerebellar ataxia-related syndromes (whether with or without a molecular diagnosis) (Lo, et al., 2015; Pineda, et al., 2010). We started a therapeutic trial in our three affected patients soon after the molecular diagnosis was made, while all were in their 20 's. The dosage used 
was $15 \mathrm{mg} / \mathrm{kg} / \mathrm{d}$ divided into three doses. Even though our patients' ataxia severity is currently mild to moderate with baseline scores ranging from 13-27/100, after 3 months of treatment their scoring was significantly reduced and ranged from 14.5/100 in the most severely affected patient and to 7.5/100 in the least severely affected. Unfortunately, the three sisters stopped their $\mathrm{CoQ}_{10}$ intake 2 weeks before the second assessment at 6 months. It is possible that the relatively higher score, showing worsening from the previous exam after 6 months of treatment (8-22/100) instead of the expected further improvement, may be attributable to the fact that they did not take the $\mathrm{CoQ}_{10}$ supplementation for 2 weeks before the second assessment. This assumption is consistent with similar experience with treatment tapering previously reported in the literature (Salviati, et al., 2012). The ICARS score, which is the more detailed scoring system used for ataxia assessment, was used in patients with $A D C K 3$ mutations, and significant improvement in the ataxia score was detected after 3 months of treatment (Montero, et al., 2007), as in our patients. Based on the significant change noticed at three months, we recommended our patients to resume the $\mathrm{CoQ}_{10}$ treatment in the current dosage, and will even consider increasing the dosage if no side effects are noticed and an attenuation in the clinical response is seen.

Variability of the clinical response to $\mathrm{CoQ}_{10}$ supplementation in the different syndromes, and within the same syndrome in different cohorts, may be related to therapeutic dosages chosen, the pharmaceutical formulation employed, the severity of the underlying illness and organs involved, the time elapsed from clinical presentation to treatment onset (with significant tissue damage already present in late treated patients), or poor tissue delivery of $\mathrm{CoQ}_{10}$ into the CNS. In addition, many other environmental and even epigenetic factors likely modulate the response to treatment (Acosta, et al., 2016; Desbats, et al., 2015; Fernandez-Ayala, et al., 2013; Trevisson, et al., 2011). It is recommended to institute treatment as early as possible, since only minimal recovery is possible once damage in critical organs (such as the kidney or the CNS) is established (Acosta, et al., 2016). The noncerebellar symptoms in our patients were much more difficult to assess because their seizures were already well-controlled by anti-epileptic drugs (AED's) and the timeframe of the treatment trial did not allow us to perform a repeated neuropsychological assessment. Nonetheless, we obtained a clinical impression of improvement in both cognitive and behavioral features.

In conclusion, primary $\mathrm{CoQ}_{10}$ deficiency due to $C O Q 5$ mutations is a treatable condition. Response to CoQ10 supplementation might be influenced by the timing of treatment, as we saw in the patients in this study. Early diagnosis by next generation sequencing in populations showing mild forms of cerebellar ataxia and static encephalomyopathy will be helpful in defining this disorder further, and evaluating the importance of early CoQ10 supplementation.

\section{Supplementary Material}

Refer to Web version on PubMed Central for supplementary material. 


\section{Acknowledgments}

The authors wish to thank the patients and their family for their cooperation and support. We also thank NISC for assisting in the initial whole exome sequencing analysis for one of the probands included in the study. This study is supported in part by the National Institutes of Health Intramural Research Program of the National Human Genome Research Institute and the Common Fund, Office of the Director; the NIH grants RO1-N5021328-030 and RO1OD010944-05; and the DOD grant, PR150585P1. RWT is supported by the Wellcome Centre for Mitochondrial Research (203105/Z/16/Z), the Medical Research Council (MRC) Centre for Translational Research in Neuromuscular Disease, Mitochondrial Disease Patient Cohort (UK) (G0800674), the Lily Foundation and the UK NHS Highly Specialised Service for Rare Mitochondrial Disorders of Adults and Children.

\section{References}

Acosta MJ, Vazquez Fonseca L, Desbats MA, Cerqua C, Zordan R, Trevisson E, Salviati L. Coenzyme Q biosynthesis in health and disease. Biochim Biophys Acta. 2016; 1857(8):1079-85. [PubMed: 27060254]

Ashraf S, Gee HY, Woerner S, Xie LX, Vega-Warner V, Lovric S, Fang H, Song X, Cattran DC, AvilaCasado C, Paterson AD, Nitschke P, Bole-Feysot C, Cochat P, Esteve-Rudd J, Haberberger B, Allen SJ, Zhou W, Airik R, Otto EA, Barua M, Al-Hamed MH, Kari JA, Evans J, Bierzynska A, Saleem MA, Bockenhauer D, Kleta R, El Desoky S, Hacihamdioglu DO, Gok F, Washburn J, Wiggins RC, Choi M, Lifton RP, Levy S, Han Z, Salviati L, Prokisch H, Williams DS, Pollak M, Clarke CF, Pei Y, Antignac C, Hildebrandt F. ADCK4 mutations promote steroid-resistant nephrotic syndrome through CoQ10 biosynthesis disruption. J Clin Invest. 2013; 123(12):5179-89. [PubMed: 24270420]

Baba SW, Belogrudov GI, Lee JC, Lee PT, Strahan J, Shepherd JN, Clarke CF. Yeast Coq5 Cmethyltransferase is required for stability of other polypeptides involved in coenzyme Q biosynthesis. J Biol Chem. 2004; 279(11):10052-9. [PubMed: 14701817]

Balreira A, Boczonadi V, Barca E, Pyle A, Bansagi B, Appleton M, Graham C, Hargreaves IP, Rasic VM, Lochmuller H, Griffin H, Taylor RW, Naini A, Chinnery PF, Hirano M, Quinzii CM, Horvath R. ANO10 mutations cause ataxia and coenzyme $\mathrm{Q}_{10}$ deficiency. Journal of neurology. 2014; 261(11):2192-8. [PubMed: 25182700]

Barkovich RJ, Shtanko A, Shepherd JA, Lee PT, Myles DC, Tzagoloff A, Clarke CF. Characterization of the COQ5 gene from Saccharomyces cerevisiae. Evidence for a C-methyltransferase in ubiquinone biosynthesis. J Biol Chem. 1997; 272(14):9182-8. [PubMed: 9083049]

Boitier E, Degoul F, Desguerre I, Charpentier C, Francois D, Ponsot G, Diry M, Rustin P, Marsac C. A case of mitochondrial encephalomyopathy associated with a muscle coenzyme Q10 deficiency. J Neurol Sci. 1998; 156(1):41-6. [PubMed: 9559985]

Brooke MH, Kaiser KK. Muscle fiber types: how many and what kind? Arch Neurol. 1970; 23(4):369_ 79. [PubMed: 4248905]

Chamova T, Florez L, Guergueltcheva V, Raycheva M, Kaneva R, Lochmuller H, Kalaydjieva L, Tournev I. ANO10 c.1150_1151del is a founder mutation causing autosomal recessive cerebellar ataxia in Roma/Gypsies. Journal of neurology. 2012; 259(5):906-11. [PubMed: 22008874]

Chen SW, Liu CC, Yen HC. Detection of suppressed maturation of the human COQ5 protein in the mitochondria following mitochondrial uncoupling by an antibody recognizing both precursor and mature forms of COQ5. Mitochondrion. 2013; 13(2):143-52. [PubMed: 23354120]

Desbats MA, Vetro A, Limongelli I, Lunardi G, Casarin A, Doimo M, Spinazzi M, Angelini C, Cenacchi G, Burlina A, Rodriguez Hernandez MA, Chiandetti L, Clementi M, Trevisson E, Navas P, Zuffardi O, Salviati L. Primary coenzyme Q10 deficiency presenting as fatal neonatal multiorgan failure. Eur J Hum Genet. 2015; 23(9):1254-8. [PubMed: 25564041]

DiMauro S, Quinzii CM, Hirano M. Mutations in coenzyme Q10 biosynthetic genes. J Clin Invest. 2007; 117(3):587-9. [PubMed: 17332886]

Dinwiddie DL, Smith LD, Miller NA, Atherton AM, Farrow EG, Strenk ME, Soden SE, Saunders CJ, Kingsmore SF. Diagnosis of mitochondrial disorders by concomitant next-generation sequencing of the exome and mitochondrial genome. Genomics. 2013; 102(3):148-56. [PubMed: 23631824]

Diomedi-Camassei F, Di Giandomenico S, Santorelli FM, Caridi G, Piemonte F, Montini G, Ghiggeri GM, Murer L, Barisoni L, Pastore A, Muda AO, Valente ML, Bertini E, Emma F. COQ2 
nephropathy: a newly described inherited mitochondriopathy with primary renal involvement. J Am Soc Nephrol. 2007; 18(10):2773-80. [PubMed: 17855635]

Doimo M, Desbats MA, Cerqua C, Cassina M, Trevisson E, Salviati L. Genetics of coenzyme q10 deficiency. Mol Syndromol. 2014; 5(3-4):156-62. [PubMed: 25126048]

Fernandez-Ayala DJ, Guerra I, Jimenez-Gancedo S, Cascajo MV, Gavilan A, Dimauro S, Hirano M, Briones P, Artuch R, De Cabo R, Salviati L, Navas P. Survival transcriptome in the coenzyme Q10 deficiency syndrome is acquired by epigenetic modifications: a modelling study for human coenzyme Q10 deficiencies. BMJ Open. 2013; 3(3)

Garrido-Maraver J, Cordero MD, Oropesa-Avila M, Fernandez Vega A, de la Mata M, Delgado Pavon A, de Miguel M, Perez Calero C, Villanueva Paz M, Cotan D, Sanchez-Alcazar JA. Coenzyme q10 therapy. Mol Syndromol. 2014; 5(3-4):187-97. [PubMed: 25126052]

Gempel K, Topaloglu H, Talim B, Schneiderat P, Schoser BG, Hans VH, Palmafy B, Kale G, Tokatli A, Quinzii C, Hirano M, Naini A, DiMauro S, Prokisch H, Lochmuller H, Horvath R. The myopathic form of coenzyme Q10 deficiency is caused by mutations in the electron-transferringflavoprotein dehydrogenase (ETFDH) gene. Brain. 2007; 130(Pt 8):2037-44. [PubMed: 17412732]

Gironi M, Lamperti C, Nemni R, Moggio M, Comi G, Guerini FR, Ferrante P, Canal N, Naini A, Bresolin N, DiMauro S. Late-onset cerebellar ataxia with hypogonadism and muscle coenzyme Q10 deficiency. Neurology. 2004; 62(5):818-20. [PubMed: 15007142]

He CH, Xie LX, Allan CM, Tran UC, Clarke CF. Coenzyme Q supplementation or over-expression of the yeast Coq8 putative kinase stabilizes multi-subunit Coq polypeptide complexes in yeast coq null mutants. Biochim Biophys Acta. 2014; 1841(4):630-44. [PubMed: 24406904]

Heeringa SF, Chernin G, Chaki M, Zhou W, Sloan AJ, Ji Z, Xie LX, Salviati L, Hurd TW, VegaWarner V, Killen PD, Raphael Y, Ashraf S, Ovunc B, Schoeb DS, McLaughlin HM, Airik R, Vlangos CN, Gbadegesin R, Hinkes B, Saisawat P, Trevisson E, Doimo M, Casarin A, Pertegato V, Giorgi G, Prokisch H, Rotig A, Nurnberg G, Becker C, Wang S, Ozaltin F, Topaloglu R, Bakkaloglu A, Bakkaloglu SA, Muller D, Beissert A, Mir S, Berdeli A, Varpizen S, Zenker M, Matejas V, Santos-Ocana C, Navas P, Kusakabe T, Kispert A, Akman S, Soliman NA, Krick S, Mundel P, Reiser J, Nurnberg P, Clarke CF, Wiggins RC, Faul C, Hildebrandt F. COQ6 mutations in human patients produce nephrotic syndrome with sensorineural deafness. J Clin Invest. 2011; 121(5):2013-24. [PubMed: 21540551]

Horvath R, Schneiderat P, Schoser BG, Gempel K, Neuen-Jacob E, Ploger H, Muller-Hocker J, Pongratz DE, Naini A, DiMauro S, Lochmuller H. Coenzyme Q10 deficiency and isolated myopathy. Neurology. 2006; 66(2):253-5. [PubMed: 16434667]

Kenyon L, Moraes CT. Expanding the functional human mitochondrial DNA database by the establishment of primate xenomitochondrial cybrids. Proc Natl Acad Sci U S A. 1997; 94(17): 9131-5. [PubMed: 9256447]

Kirby DM, Thorburn DR, Turnbull DM, Taylor RW. Biochemical assays of respiratory chain complex activity. Methods Cell Biol. 2007; 80:93-119. [PubMed: 17445690]

Lagier-Tourenne C, Tazir M, Lopez LC, Quinzii CM, Assoum M, Drouot N, Busso C, Makri S, AliPacha L, Benhassine T, Anheim M, Lynch DR, Thibault C, Plewniak F, Bianchetti L, Tranchant C, Poch O, DiMauro S, Mandel JL, Barros MH, Hirano M, Koenig M. ADCK3, an ancestral kinase, is mutated in a form of recessive ataxia associated with coenzyme Q10 deficiency. Am J Hum Genet. 2008; 82(3):661-72. [PubMed: 18319074]

Lalani SR, Vladutiu GD, Plunkett K, Lotze TE, Adesina AM, Scaglia F. Isolated mitochondrial myopathy associated with muscle coenzyme Q10 deficiency. Arch Neurol. 2005; 62(2):317-20. [PubMed: 15710863]

Livak KJ, Schmittgen TD. Analysis of relative gene expression data using real-time quantitative PCR and the 2(-Delta Delta C(T)) Method. Methods. 2001; 25(4):402-8. [PubMed: 11846609]

Lo RY, Figueroa KP, Pulst SM, Lin CY, Perlman S, Wilmot G, Gomez C, Schmahmann J, Paulson H, Shakkottai VG, Ying S, Zesiewicz T, Bushara K, Geschwind M, Xia G, Subramony SH, Ashizawa T, Kuo SH. Coenzyme Q10 and spinocerebellar ataxias. Mov Disord. 2015; 30(2):214-20. [PubMed: 25449974]

Malicdan MCV, Vilboux T, Stephen J, Maglic D, Mian L, Konzman D, Guo J, Yildirimli D, Bryant J, Fischer R, Zein WM, Snow J, Vemulapalli M, Mullikin JC, Toro C, Solomon BD, Niederhuber JE, 
Gahl WA, Gunay-Aygun M, Progra NCS. Mutations in human homologue of chicken talpid3 gene (KIAA0586) cause a hybrid ciliopathy with overlapping features of Jeune and Joubert syndromes. Journal of Medical Genetics. 2015; 52(12):830-839. [PubMed: 26386044]

Maruyama H, Morino H, Miyamoto R, Murakami N, Hamano T, Kawakami H. Exome sequencing reveals a novel ANO10 mutation in a Japanese patient with autosomal recessive spinocerebellar ataxia. Clinical genetics. 2014; 85(3):296-7. [PubMed: 23551081]

McCarthy HJ, Bierzynska A, Wherlock M, Ognjanovic M, Kerecuk L, Hegde S, Feather S, Gilbert RD, Krischock L, Jones C, Sinha MD, Webb NJ, Christian M, Williams MM, Marks S, Koziell A, Welsh GI, Saleem MA. Group RtUSS. Simultaneous sequencing of 24 genes associated with steroid-resistant nephrotic syndrome. Clin J Am Soc Nephrol. 2013; 8(4):637-48. [PubMed: 23349334]

Mignot C, Apartis E, Durr A, Marques Lourenco C, Charles P, Devos D, Moreau C, de Lonlay P, Drouot N, Burglen L, Kempf N, Nourisson E, Chantot-Bastaraud S, Lebre AS, Rio M, Chaix Y, Bieth E, Roze E, Bonnet I, Canaple S, Rastel C, Brice A, Rotig A, Desguerre I, Tranchant C, Koenig M, Anheim M. Phenotypic variability in ARCA2 and identification of a core ataxic phenotype with slow progression. Orphanet J Rare Dis. 2013; 8:173. [PubMed: 24164873]

Mollet J, Delahodde A, Serre V, Chretien D, Schlemmer D, Lombes A, Boddaert N, Desguerre I, de Lonlay P, de Baulny HO, Munnich A, Rotig A. CABC1 gene mutations cause ubiquinone deficiency with cerebellar ataxia and seizures. Am J Hum Genet. 2008; 82(3):623-30. [PubMed: 18319072]

Montero R, Pineda M, Aracil A, Vilaseca MA, Briones P, Sanchez-Alcazar JA, Navas P, Artuch R. Clinical, biochemical and molecular aspects of cerebellar ataxia and Coenzyme Q10 deficiency. Cerebellum. 2007; 6(2):118-22. [PubMed: 17510911]

Montini G, Malaventura C, Salviati L. Early coenzyme Q10 supplementation in primary coenzyme Q10 deficiency. N Engl J Med. 2008; 358(26):2849-50. [PubMed: 18579827]

Mozaffar T, Pestronk A. Myopathy with anti-Jo-1 antibodies: pathology in perimysium and neighbouring muscle fibres. J Neurol Neurosurg Psychiatry. 2000; 68(4):472-8. [PubMed: 10727483]

Musumeci O, Naini A, Slonim AE, Skavin N, Hadjigeorgiou GL, Krawiecki N, Weissman BM, Tsao CY, Mendell JR, Shanske S, De Vivo DC, Hirano M, DiMauro S. Familial cerebellar ataxia with muscle coenzyme Q10 deficiency. Neurology. 2001; 56(7):849-55. [PubMed: 11294920]

Naini A, Lewis VJ, Hirano M, DiMauro S. Primary coenzyme Q10 deficiency and the brain. Biofactors. 2003; 18(1-4):145-52. [PubMed: 14695930]

Nguyen TP, Casarin A, Desbats MA, Doimo M, Trevisson E, Santos-Ocana C, Navas P, Clarke CF, Salviati L. Molecular characterization of the human COQ5 C-methyltransferase in coenzyme Q10 biosynthesis. Biochim Biophys Acta. 2014; 1841(11):1628-38. [PubMed: 25152161]

Ogasahara S, Engel AG, Frens D, Mack D. Muscle coenzyme Q deficiency in familial mitochondrial encephalomyopathy. Proc Natl Acad Sci U S A. 1989; 86(7):2379-82. [PubMed: 2928337]

Peiffer DA, Le JM, Steemers FJ, Chang W, Jenniges T, Garcia F, Haden K, Li J, Shaw CA, Belmont J, Cheung SW, Shen RM, Barker DL, Gunderson KL. High-resolution genomic profiling of chromosomal aberrations using Infinium whole-genome genotyping. Genome Res. 2006; 16(9): 1136-48. [PubMed: 16899659]

Pestronk GJ, Kaiser KK, Brooke MH. ATPase stain in muscle histochemistry. Muscle Nerve. 1992; 15(2):258. [PubMed: 1372392]

Pineda M, Montero R, Aracil A, O'Callaghan MM, Mas A, Espinos C, Martinez-Rubio D, Palau F, Navas P, Briones P, Artuch R. Coenzyme Q(10)-responsive ataxia: 2-year-treatment follow-up. Mov Disord. 2010; 25(9):1262-8. [PubMed: 20629161]

Quinzii C, Naini A, Salviati L, Trevisson E, Navas P, Dimauro S, Hirano M. A mutation in parahydroxybenzoate-polyprenyl transferase (COQ2) causes primary coenzyme Q10 deficiency. Am J Hum Genet. 2006; 78(2):345-9. [PubMed: 16400613]

Quinzii CM, Emmanuele V, Hirano M. Clinical presentations of coenzyme q10 deficiency syndrome. Mol Syndromol. 2014; 5(3-4):141-6. [PubMed: 25126046] 
Quinzii CM, Kattah AG, Naini A, Akman HO, Mootha VK, DiMauro S, Hirano M. Coenzyme Q deficiency and cerebellar ataxia associated with an aprataxin mutation. Neurology. 2005; 64(3): 539-41. [PubMed: 15699391]

Rossignol R, Malgat M, Mazat JP, Letellier T. Threshold effect and tissue specificity - Implication for mitochondrial cytopathies. Journal of Biological Chemistry. 1999; 274(47):33426-33432. [PubMed: 10559224]

Rotig A, Appelkvist EL, Geromel V, Chretien D, Kadhom N, Edery P, Lebideau M, Dallner G, Munnich A, Ernster L, Rustin P. Quinone-responsive multiple respiratory-chain dysfunction due to widespread coenzyme Q10 deficiency. Lancet. 2000; 356(9227):391-5. [PubMed: 10972372]

Salviati L, Sacconi S, Murer L, Zacchello G, Franceschini L, Laverda AM, Basso G, Quinzii C, Angelini C, Hirano M, Naini AB, Navas P, DiMauro S, Montini G. Infantile encephalomyopathy and nephropathy with CoQ10 deficiency: a CoQ10-responsive condition. Neurology. 2005; 65(4): 606-8. [PubMed: 16116126]

Salviati L, Trevisson E, Rodriguez Hernandez MA, Casarin A, Pertegato V, Doimo M, Cassina M, Agosto C, Desbats MA, Sartori G, Sacconi S, Memo L, Zuffardi O, Artuch R, Quinzii C, Dimauro S, Hirano M, Santos-Ocana C, Navas P. Haploinsufficiency of COQ4 causes coenzyme Q10 deficiency. J Med Genet. 2012; 49(3):187-91. [PubMed: 22368301]

Sobreira C, Hirano M, Shanske S, Keller RK, Haller RG, Davidson E, Santorelli FM, Miranda AF, Bonilla E, Mojon DS, Barreira AA, King MP, DiMauro S. Mitochondrial encephalomyopathy with coenzyme Q10 deficiency. Neurology. 1997; 48(5):1238-43. [PubMed: 9153450]

Sommerville RB, Zaidman CM, Pestronk A. Coenzyme Q10 deficiency in children: frequent type 2C muscle fibers with normal morphology. Muscle Nerve. 2013; 48(5):722-6. [PubMed: 23494902]

Staron RS, Hagerman FC, Hikida RS, Murray TF, Hostler DP, Crill MT, Ragg KE, Toma K. Fiber type composition of the vastus lateralis muscle of young men and women. J Histochem Cytochem. 2000; 48(5):623-9. [PubMed: 10769046]

Steemers FJ, Gunderson KL. Whole genome genotyping technologies on the BeadArray platform. Biotechnol J. 2007; 2(1):41-9. [PubMed: 17225249]

Suzuki K, Bose P, Leong-Quong RY, Fujita DJ, Riabowol K. REAP: A two minute cell fractionation method. BMC research notes. 2010; 3:294. [PubMed: 21067583]

Taylor RW, Birch-Machin MA, Bartlett K, Turnbull DM. Succinate-cytochrome c reductase: assessment of its value in the investigation of defects of the respiratory chain. Biochim Biophys Acta. 1993; 1181(3):261-5. [PubMed: 8391327]

Teer JK, Green ED, Mullikin JC, Biesecker LG. VarSifter: visualizing and analyzing exome-scale sequence variation data on a desktop computer. Bioinformatics. 2012; 28(4):599-600. [PubMed: 22210868]

Trevisson E, DiMauro S, Navas P, Salviati L. Coenzyme Q deficiency in muscle. Curr Opin Neurol. 2011; 24(5):449-56. [PubMed: 21844807]

Trouillas P, Takayanagi T, Hallett M, Currier RD, Subramony SH, Wessel K, Bryer A, Diener HC, Massaquoi S, Gomez CM, Coutinho P, Ben Hamida M, Campanella G, Filla A, Schut L, Timann D, Honnorat J, Nighoghossian N, Manyam B. International Cooperative Ataxia Rating Scale for pharmacological assessment of the cerebellar syndrome. The Ataxia Neuropharmacology Committee of the World Federation of Neurology. J Neurol Sci. 1997; 145(2):205-11. [PubMed: 9094050]

Vilboux T, Ciccone C, Blancato JK, Cox GF, Deshpande C, Introne WJ, Gahl WA, Smith AC, Huizing M. Molecular analysis of the Retinoic Acid Induced 1 gene (RAI1) in patients with suspected Smith-Magenis syndrome without the 17p11.2 deletion. PLoS One. 2011; 6(8):e22861. [PubMed: 21857958]

Yen HC, Liu YC, Kan CC, Wei HJ, Lee SH, Wei YH, Feng YH, Chen CW, Huang CC. Disruption of the human COQ5-containing protein complex is associated with diminished coenzyme Q10 levels under two different conditions of mitochondrial energy deficiency. Biochim Biophys Acta. 2016; 1860(9):1864-76. [PubMed: 27155576]

Yubero D, Montero R, Artuch R, Land JM, Heales SJ, Hargreaves IP. Biochemical diagnosis of coenzyme q10 deficiency. Mol Syndromol. 2014; 5(3-4):147-55. [PubMed: 25126047] 
A
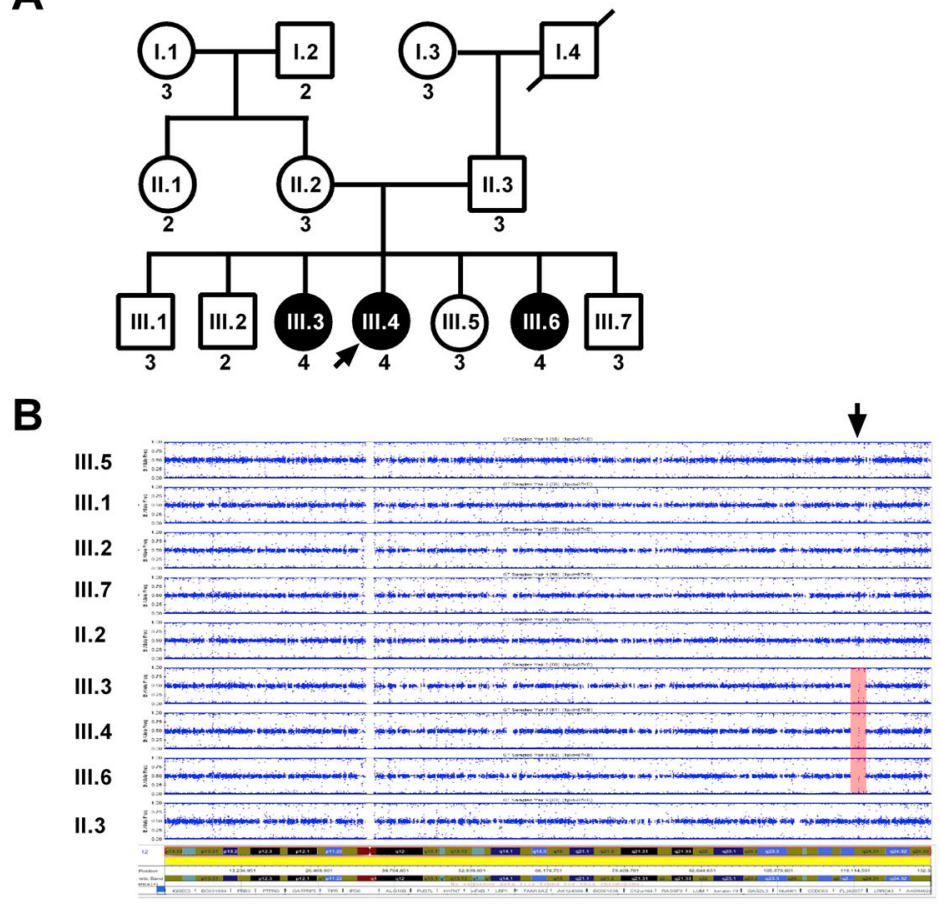

C

Chr12: 118.5Mb-121Mb

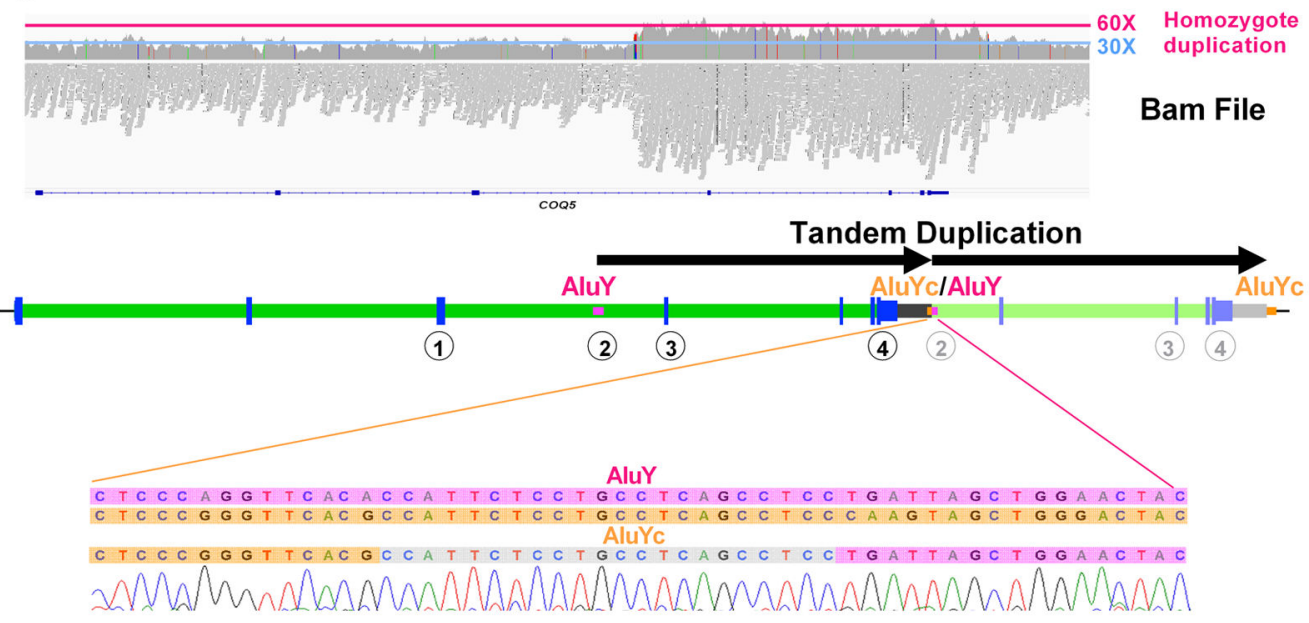

Fig. 1. Patients included in the study

(A) Family pedigree. Patients who are affected are shown in filled circles. Male individuals are represented by squares, while female individuals are represented by circles. (B) SNP data analysis of all members of the family shows a single homozygous region, from $118.5 \mathrm{Mb}-121 \mathrm{Mb}$ on chromosome 12 (hg19) (arrow).

(C) Whole genome sequencing on III.4 was inconclusive, but analysis of Bam file shows an increase of the number of reads in the candidate locus on chromosome 12 between positions $\sim 120,940,150$ and $\sim 120,949,950$, with an average number of reads of $\sim 60 \mathrm{X}$ compared to the rest of the region $(\sim 30 \mathrm{X})$. A cartoon below the Bam file shows the duplication in tandem, breakpoints confirmed by Sanger sequencing), between an AluYc (chr12:120939934120940228) and an AluY (chr12:120949733-120950042). The encircled numbers below the 
gene show the positions of the different Taqman probes used for testing the copy number of the duplicated region, which is shown in (A) as the number below each box or circle. 
A

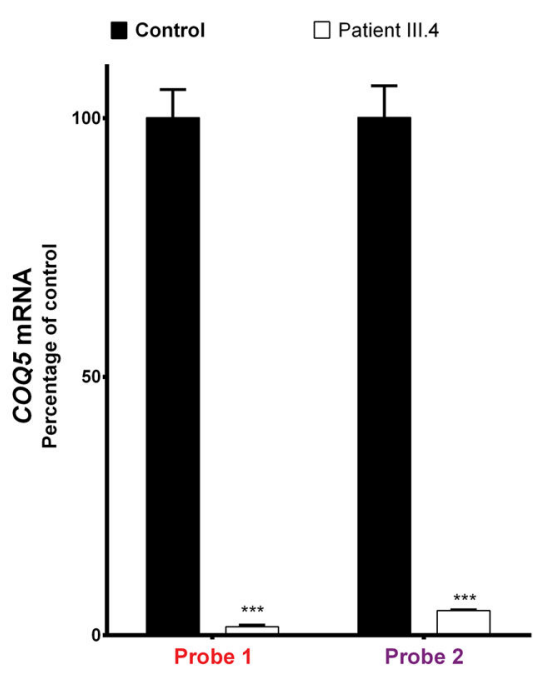

B
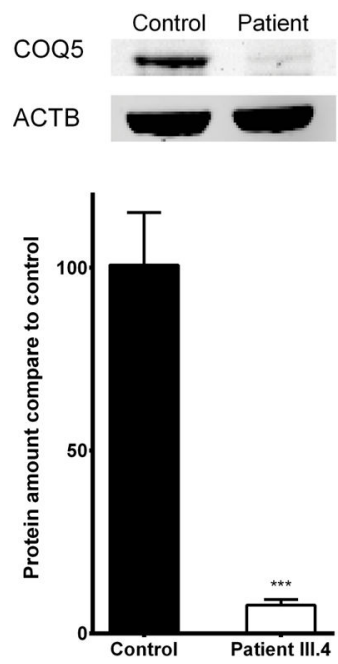

C
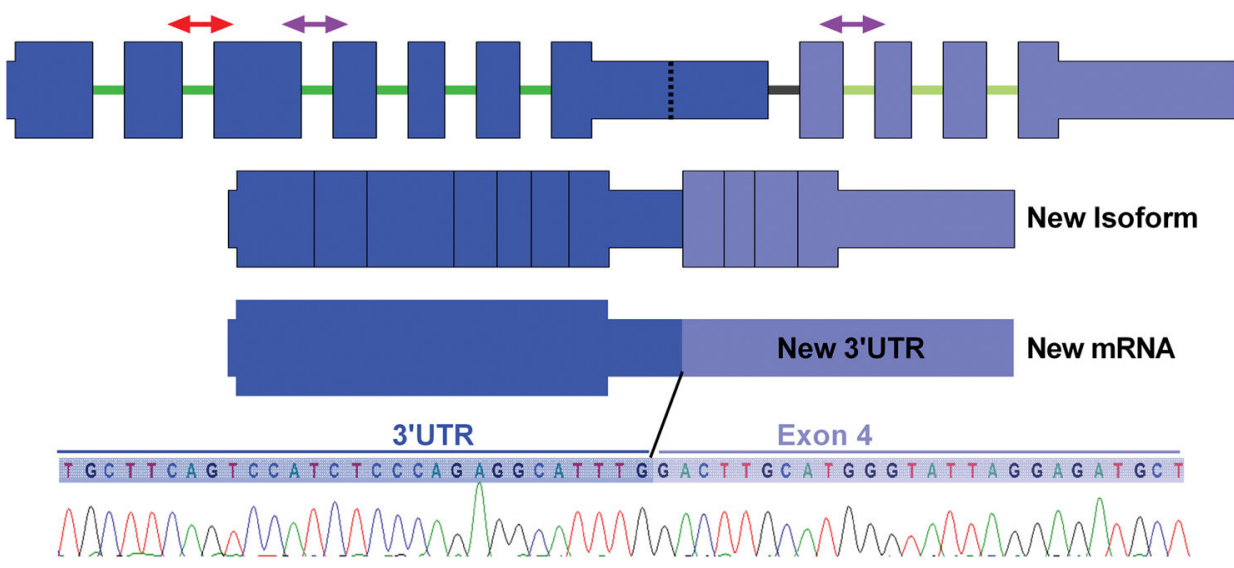

Fig. 2. Effects of $C O Q 5$ mutation in RNA and protein from fibroblasts

(A) Quantitative real-time PCR results for the expression of three COQ5 mRNA isoforms in fibroblasts from patient compared with control. Values are percentage expression of COQ5 in patient fibroblasts compared with control fibroblasts, normalized to POLR2A (error bars represent S.D., n=3). (B) Quantification of the expression of COQ5 protein in patient fibroblasts and control fibroblasts. Values are relative expression of COQ5 normalized to the loading control ACTB (error bars represent S.D., $n=3$ from two independent experiments). Next to the histogram is the immunoblot of fibroblast whole cell lysates of patient and control, showing the decreased expression of COQ5 in the patient. (C) A diagram of the known COQ5 isoform (NM_032314.3) is shown, and regions amplified by qPCR analysis in (A) are marked with arrows (red represents Probe 1, and violet represents Probe 2). Below the normal COQ5 isoform is a diagram depicting a new isoform generated. Sequencing of the cDNA from fibroblasts of patient III.4 shows an abnormal 3'UTR because of an abnormal splicing event: part of the original $3^{\prime}$ UTR has been spliced off and replaced by the duplicated part of the gene (Exon 4 to 7), depicted in the figure as "New mRNA". At the 
bottom of the figure is a chromatogram that shows the nucleotide sequence between the $3^{\prime}$ UTR and the duplicated part of the gene, beginning from exon 4. 
A

\begin{tabular}{|c|c|c|c|c|}
\hline \multirow[t]{2}{*}{$\begin{array}{l}\text { Patient } \\
\text { number }\end{array}$} & \multirow[t]{2}{*}{ Status } & \multicolumn{2}{|c|}{$\begin{array}{l}\text { Leukocyte Coenzyme Q10 levels baseline } \\
\text { (pmol/ug protein; normal range }=119.86 \pm 24.23 \text { ) }\end{array}$} & \multirow{2}{*}{$\begin{array}{l}\text { Coenzyme Q10 levels in } \\
\text { skeletal muscle (26.63- } \\
48.11 \text { ug/g tissue) }\end{array}$} \\
\hline & & Baseline & $\begin{array}{c}3 \text { months after } \\
\text { treatment }\end{array}$ & \\
\hline 11.2 & Unaffected & 117 & 93 & Not done \\
\hline III.3 & Affected & 78 & 332 & Not done \\
\hline III.4 & Affected & 65 & 293 & 21.53 \\
\hline 111.6 & Affected & 72 & 279 & Not done \\
\hline
\end{tabular}

B

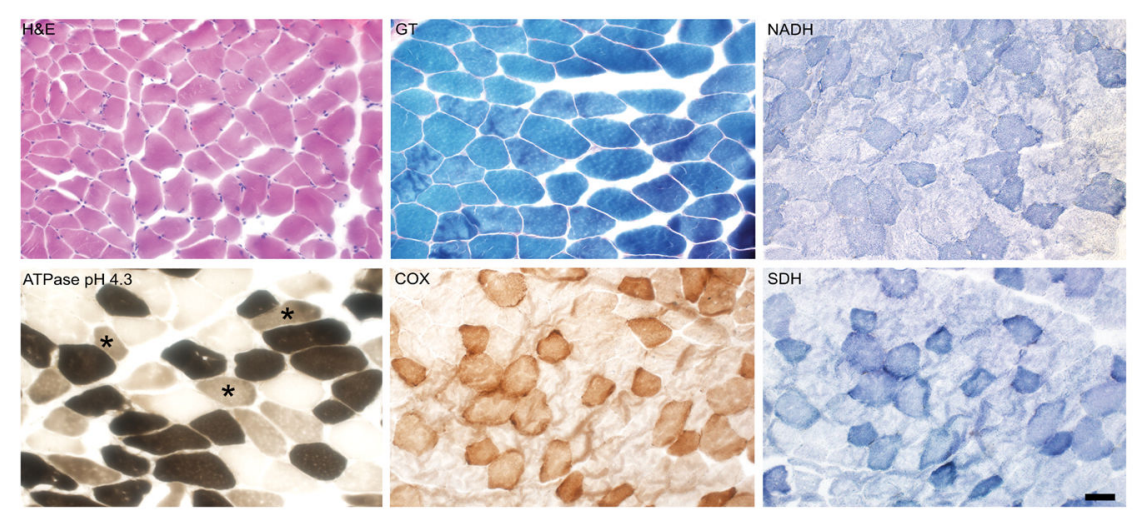

C

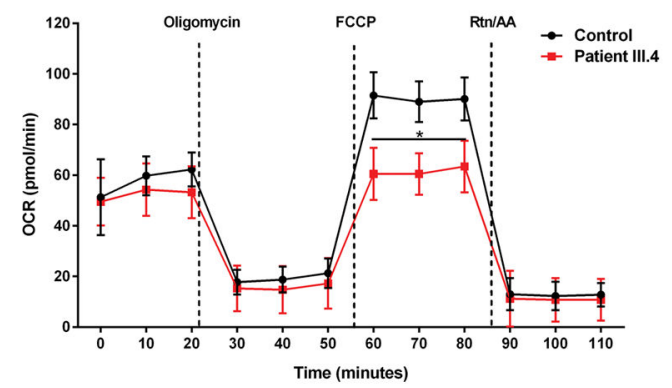

D

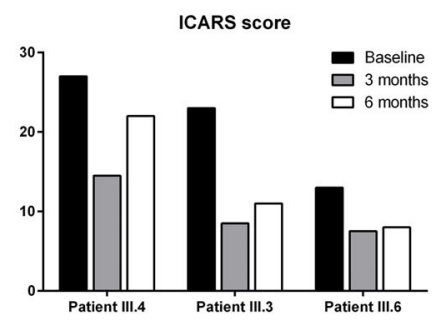

Fig. 3. COQ5 mutation reduces CoQ10 levels and lead to abnormal mitochondrial respiration (A) Table showing CoQ10 levels in leukocytes from patients III.3, III.4, and III.6. Baseline levels and levels at 3 months after initiation of oral CoQ10 treatment are shown. Range of normal values was the average from 14 individuals with no known mitochondrial defect or mutations in the COQ genes. Level of Coenzyme Q10 levels in skeletal muscle in II.4 is also shown. (B) Representative muscle histopathology slides showing hematoxylin and eosin (H\&E), Gomori trichrome (GT), nicotinamide adenine dinucleotide (NADH), cytochrome oxidase (COX) and succinate dehydrogenase (SDH) stains. The morphology of muscle fibers appears normal. Myosin adenosine tri-phosphatase (ATPase) activity staining at $\mathrm{pH}$ 4.3 identifies type $2 \mathrm{C}$ (immature) muscle fibers with an intermediate staining intensity between dark, type 1 (slow, oxidative) and light, type 2 (fast, glycolytic) fibers. Many type 2C muscle fibers are seen (asterisks). Scale bar represents $50 \mu \mathrm{m}$.

(C) Cellular oxygen consumption rates (OCR) for fibroblast cell lines from wild-type (WT) and COQ5 patient (III.4) were measured by XF24 extracellular flux analysis. Oligomycin $(1.25 \mu \mathrm{M})$, carbonyl cyanide 4-(trifluoromethoxy) phenylhydrazone (FCCP, $0.2 \mu \mathrm{M})$, and 
antimycin $\mathrm{A}(\mathrm{AA}, 1.8 \mu \mathrm{M})$ together with Rotenone $(\mathrm{Rtn}, 1 \mu \mathrm{M})$ were injected after 20,50 and 80 minutes, respectively (n 4 plates; $*$ p. value $<0.05$ ).

(D) Clinical scoring (ICARS) before and during CoQ10 treatment. 